\title{
Synthesis and Structural Characterization of $\mathrm{BaTiO}_{3}-\mathrm{SiO}_{2}$ Aerogels
}

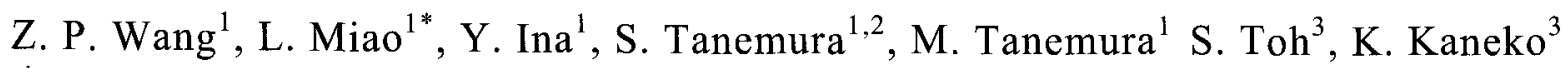 \\ ${ }^{1}$ Department of Environmental Technology, Graduate School of Engineering, Nagoya Institute of Technology, \\ Gokiso-cho, Showa-ku, Nagoya 466-8555, JAPAN \\ ${ }^{2}$ Materials R\&D Laboratory, Japan Fine Ceramics Centre, 2-4-1 Mutsuno, Atsuta-ku, Nagoya 456-8587, Japan \\ ${ }^{3}$ Department of Materials Science and Engineering, HVEM Lab., Kyushu University, Hakozaki 6-10-1, Higasi-ku, \\ Fukuoka 812-8581, Japan \\ Fax: 81-52-735-5024,*e-mail:miao.lei@nitech.ac.jp
}

\begin{abstract}
BaTiO}_{3}-\mathrm{SiO}_{2}$ aerogels were prepared by sol-gel route with supercritical drying technique, after silica wet gel was dipped into $\mathrm{BaTiO}_{3}$ solution. In order to compare with the properties of compounded aerogels, pure $\mathrm{BaTiO}_{3}$ nanoparticles were also prepared by the sol-gel method. These $\mathrm{BaTiO}_{3}-\mathrm{SiO}_{2}$ aerogels and $\mathrm{BaTiO}_{3}$ nanoparticles were characterized by X-ray diffraction (XRD), Raman spectra, transmission electron microscopy (TEM) and photoluminescence (PL) spectra. The size of compounded aerogel nanoparticles distributed from 7 to $20 \mathrm{~nm}$ when the $\mathrm{BaTiO}_{3}-\mathrm{SiO}_{2}$ aerogels were heated at $800{ }^{\circ} \mathrm{C}$. The intensity of $\mathrm{PL}$ was obviously increased, comparing with the one of pure $\mathrm{BaTiO}_{3}$ heated at the same temperature.
\end{abstract}

Key words: $\mathrm{BaTiO}_{3}$, compounded aerogels, photoluminescence, supercritical drying method

\section{INTRODUCTION}

It is well known that aerogel is a fractal type of network material with high surface areas, low density and high porosities ${ }^{[1]}$. These materials are extremely interesting and many commercial applications have been found, such as insulators, water purification, optic coating, optics and so on ${ }^{[2]}$. Silica aerogel is one kind of these materials. There are many important attributes about silica aerogel in catalytic, insulating and optical properties ${ }^{[3,4]}$. At the same time, silica aerogel is used as the matrix for other kinds of researches, for example narrow-band-gap semiconductors doped into silica aerogel to improve the optical properties ${ }^{[5]}, \mathrm{GeO}_{2}$ doped silica aerogel in order to raise the refractive index ${ }^{[6]}$.

Due to their wide variety of physical properties such as piezoelectricity, ferroelectricity and electro-optic effect, perovskite-type oxides have seen an explosion of interest over the last few years. Barium titanate $\left(\mathrm{BaTiO}_{3}\right)$ as a typical perovskite material has been attractive for its fundamental research and perspective applications. $\mathrm{BaTiO}_{3}$ is negative uniaxial crystal when it is tetragonal phase and the nonlinear optical properties of barium titanate were already known 40 years ago ${ }^{[7]}$. Recently the nonlinear optical properties of $\mathrm{BaTiO}_{3}$ embedded by noble metal nanoparticles were investigated because barium titanate thin films have high dielectric constants, which could strongly influence the local fields around the metal particles ${ }^{[8]}$. But to the best of our knowledge, no work has been reported about the optical properties of $\mathrm{BaTiO}_{3}$ nanocrystals doped into silica aerogel up to now.

For the sake of $\mathrm{BaTiO}_{3}$ nanoparticles doped into silica aerogel, ultrafine $\mathrm{BaTiO}_{3}$ nanoparticles were required to obtain at first. The production and characterization about $\mathrm{BaTiO}_{3}$ have been performed by many researchers. Nanocrystalline $\mathrm{BaTiO}_{3}$ powder has been prepared by various methods ${ }^{[9]}$, such as solid phase method and gas phase reaction ${ }^{[10]}$. But the most popular methods for preparing $\mathrm{BaTiO}_{3}$ nanoparticles are liquid phase processes such as hydrothermal method, sol-gel method, micro-emulsion method and low temperature direct synthesis ${ }^{[10]}$. It was reported that the ultrafine $\mathrm{BaTiO}_{3}$ powder with an average size of approximately $7 \mathrm{~nm}$ had been produced ${ }^{[1]}$. Nevertheless, Uchino et al. ${ }^{[12]}$ reported the disappearance of the tetragonal ferroelectric structure below a critical size of $120 \mathrm{~nm}$ at the room temperature. Frey et al. ${ }^{[13]}$ observed no electric hysteresis with $25 \mathrm{~nm}$ crystals and no anomaly of the dielectric constant at the Curie point.

To keep the tetragonal phase of $\mathrm{BaTiO}_{3}$, which has ferroelectricity, a possible strategy is to introduce the $\mathrm{BaTiO}_{3}$ solution into the silica aerogel matrix. The supercritical drying technique may be a suitable method for preparation of silica aerogel doped with $\mathrm{BaTiO}_{3}$. In this paper, with the supercritical drying method, some fractions of $\mathrm{BaTiO}_{3}$ nanoparticles have been successfully incorporated into silica aerogel, $\mathrm{BaTiO}_{3}-\mathrm{SiO}_{2}$ compounded aerogels can be obtained.

\section{EXPERIMENTAL}

$\mathrm{Ba}(\mathrm{OH})_{2} \cdot 8 \mathrm{H}_{2} \mathrm{O}$, acetic acid, isopropanol, titanium tetraisopropoxide(TTIP), tetramethyl orthosilicate (TMOS), ethanol and ammonia solution were adopted as starting materials for preparation of $\mathrm{BaTiO}_{3}-\mathrm{SiO}_{2}$ aerogels through sol-gel and the supercritical drying process. The flow chart of $\mathrm{BaTiO}_{3}-\mathrm{SiO}_{2}$ aerogels synthesis used in this study is outlined in Fig.1.

Firstly silica wet gel was produced in a one-step synthesis method by hydrolysis and polycondensation of TMOS diluted in a solvent ethanol using ammonium hydroxide $\left(\mathrm{NH}_{4} \mathrm{OH}\right.$ at $\left.0.1 \mathrm{~mol} / \mathrm{l}\right)$ as a catalyst with aging for $10 \mathrm{hrs} . \mathrm{BaTiO}_{3}$ precursor solution was prepared from $\mathrm{Ba}(\mathrm{OH}){ }_{2} \cdot 8 \mathrm{H}_{2} \mathrm{O}$, acetic acid, isopropanol and TTIP according to the following method: $\mathrm{Ba}(\mathrm{OH})_{2} \bullet 8 \mathrm{H}_{2} \mathrm{O}$ was dissolved by stirring and heating in a 1:1 mixed solution of acetic acid and isopropanol for 30 minutes. Then a stoichiometric amount of TTIP was added dropwise after cooling this solution to room temperature. After stirring a few minutes a clear 


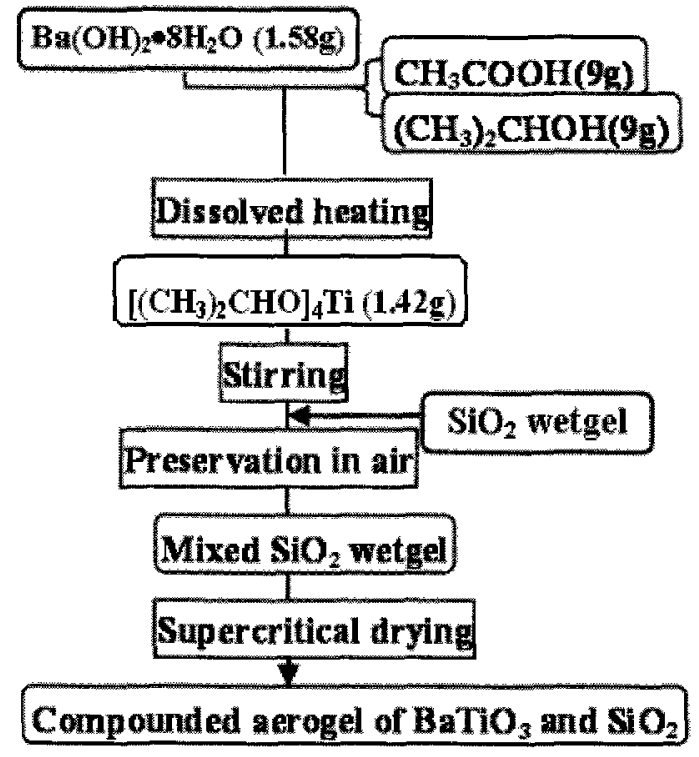

Fig.1 Flow-chart illustrating the procedure for the preparation of $\mathrm{BaTiO}_{3}-\mathrm{SiO}_{2}$ aerogels

solution was obtained. Then silica wet gel was dipped into $\mathrm{BaTiO}_{3}$ precursor solution for $24 \mathrm{hrs}$ in order to form the compounded wetgels. $\mathrm{BaTiO}_{3}-\mathrm{SiO}_{2}$ compounded aerogels were obtained through the supercritical drying process with liquid $\mathrm{CO}_{2}$ as drying medium. Then the samples were heated at $600^{\circ} \mathrm{C}, 700^{\circ} \mathrm{C}$ and $800^{\circ} \mathrm{C}$ and kept for $2 \sim 10$ hrs for crystal growth respectively. In order to analyze the properties of $\mathrm{BaTiO}_{3}-\mathrm{SiO}_{2}$ aerogels powder, pure $\mathrm{BaTiO}_{3}$ powder was obtained from $\mathrm{BaTiO}_{3}$ gels by sol-gel method, which were heated at $600^{\circ} \mathrm{C}, 700^{\circ} \mathrm{C}$, $800^{\circ} \mathrm{C}$ and $900^{\circ} \mathrm{C}$ respectively.

$\mathrm{S} 1, \mathrm{~S} 2, \mathrm{~S} 3$ and S4 were defined the samples of pure $\mathrm{BaTiO}_{3}$ powder obtained when $\mathrm{BaTiO}_{3}$ wet gels were heated at $600^{\circ} \mathrm{C}, 700^{\circ} \mathrm{C}, 800^{\circ} \mathrm{C}$ and $900^{\circ} \mathrm{C}$, respectively. $\mathrm{S} 5$ and $\mathrm{S} 6$ were defined the samples of $\mathrm{BaTiO}_{3}-\mathrm{SiO}_{2}$ aerogels heated at $800^{\circ} \mathrm{C}$ and unheated at room temperature, respectively. The test and measurement for $\mathrm{S} 1, \mathrm{~S} 2, \mathrm{~S} 3, \mathrm{~S} 4, \mathrm{~S} 5$ and S6 were listed in table I.

Tab. I The list of test and measurement for the samples

\begin{tabular}{|c|c|c|c|c|c|c|}
\hline & S1 & S2 & S3 & S4 & S5 & S6 \\
\hline XRD & O & O & O & O & O & O \\
\hline Raman & & O & & & & \\
\hline TEM & & O & & & O & \\
\hline PL & & O & O & & O & \\
\hline
\end{tabular}

O showed that the sample was tested in this work.

Identification of synthesized phase and estimation of crystalline size of $\mathrm{BaTiO}_{3}-\mathrm{SiO}_{2}$ aerogel powder and $\mathrm{BaTiO}_{3}$ powder were investigated by powder XRD measurement. XRD data was recorded on a diffractometer (Model RINT2000, Rigaku Co., Tokyo, Japan), using CuK $\alpha 1$ radiation, and collected over a $2 \theta$ range of $10^{\circ} \sim 80^{\circ}$ with a scanning step of $0.01^{\circ}$ at room temperature. The average size and morphology of $\mathrm{BaTiO}_{3}-\mathrm{SiO}_{2}$ aerogels and $\mathrm{BaTiO}_{3}$ particles were observed by TEM. The Raman spectroscopy, with the $1064 \mathrm{~nm}$ lines of the exciting source from an $\mathrm{Nd}-\mathrm{YAG}$ laser was used for the phase identification. The PL spectrum was taken with $325.0 \mathrm{~nm}$ exciting wavelength of an argon ion laser.

\section{RESULTS and DISCUSSION}

3. 1 Structural characterization

Fig. 2 shows the XRD patterns of pure $\mathrm{BaTiO}_{3}$ powder heat treated at different temperature ranging from 600 to $900^{\circ} \mathrm{C}$ o Yong-I. Kim et al $^{[14]}$ reported that the tetragonal phase has two peaks, (002) and (200), which are clearly separated near $2 \theta=45^{\circ}$, while only (200) peak of the cubic phase lies between tetragonal peaks, however, if the size of crystallite decreases, the separated two peaks of tetragonal phase may be overlapped because of he broadening of diffraction peaks. Fig. 2 shows that the peak shapes of pure $\mathrm{BaTiO}_{3}$ powder are not obviously changed except for the peaks intensities when the heat treatment temperature is increased. In order to prove whether the tetragonal phase exists in pure $\mathrm{BaTiO}_{3}$ powder or not, the measurement of Raman spectrum had been done.

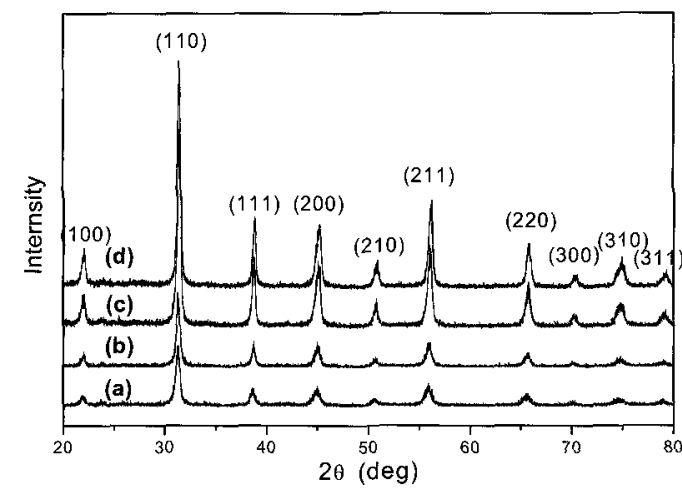

Fig.2 the XRD patterns of pure $\mathrm{BaTiO}_{3}$ powder heat treated at $600^{\circ} \mathrm{C} \mathrm{(a),} 700^{\circ} \mathrm{C} \mathrm{(b)}, 800^{\circ} \mathrm{C}(\mathrm{c})$ and $900^{\circ} \mathrm{C}(\mathrm{d})$ respectively.

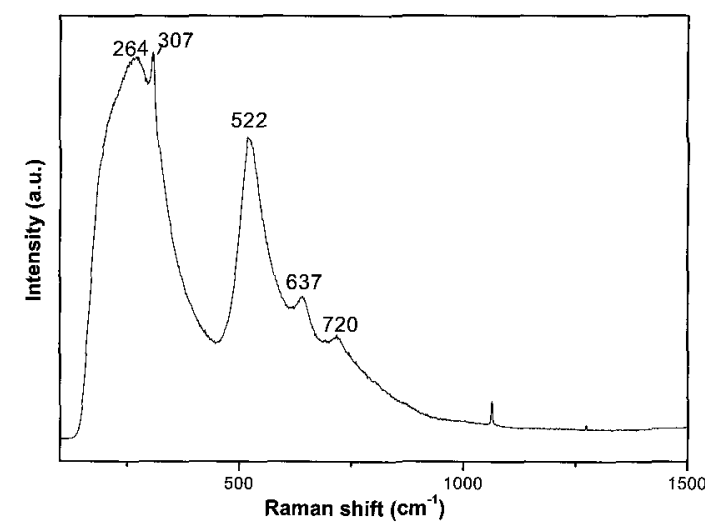

Fig. 3 Raman spectra of $\mathrm{BaTiO}_{3}$ powder heat treated at $700^{\circ} \mathrm{C}$ 
Fig. 3 shows the Raman spectrum of $\mathrm{BaTiO}_{3}$ powder heat treated at $700^{\circ} \mathrm{C}$. From the Raman spectrum, it could be found that Raman spectrum of the powder contains the Raman peaks corresponding to the cubic and tetragonal phases. The peak around $307 \mathrm{~cm}^{-1[14,15]}$ is a typical one for the tetragonal $\mathrm{BaTiO}_{3}$, while the peak at $522 \mathrm{~cm}^{-1[14,15]}$ is characterized as one of the cubic phase in $\mathrm{BaTiO}_{3}$. The result of Raman spectrum supports that pure $\mathrm{BaTiO}_{3}$ powder in this work contains both cubic and tetragonal phases.

The XRD patterns of $\mathrm{BaTiO}_{3}-\mathrm{SiO}_{2}$ aerogels at room temperature and heated at $800^{\circ} \mathrm{C}$ are shown in Fig.4. There is only peak in the XRD pattern of $\mathrm{BaTiO}_{3}-\mathrm{SiO}_{2}$ aerogels (a) at room temperature, because it comes from the amorphous $\mathrm{SiO}_{2}$. It shows that the $\mathrm{BaTiO}_{3}-\mathrm{SiO}_{2}$ aerogels at room temperature are amorphous. The $\mathrm{BaTiO}_{3}$ nanocrystals were obtained in compounded aerogels when $\mathrm{BaTiO}_{3}-\mathrm{SiO}_{2}$ aerogels were heated at $800^{\circ} \mathrm{C}$, which can be concluded from the sharpness of the diffraction peaks (b). Fig.5 shows the electron diffraction pattern of $\mathrm{BaTiO}_{3}-\mathrm{SiO}_{2}$ aerogels heat treated at $800^{\circ} \mathrm{C}$. Polycrystalline structures of $\mathrm{BaTiO}_{3}-\mathrm{SiO}_{2}$ aerogels can be identified from the rings clearly seen in Fig.5. Fig. 4 shows that the peak positions of XRD patterns in $\mathrm{BaTiO}_{3}-\mathrm{SiO}_{2}$ aerogels were different from the ones in pure $\mathrm{BaTiO}_{3}$ powder. It was speculated that the $\mathrm{BaTiO}_{3}$ nanocrystals were obtained, simultaneously new compound generated when the $\mathrm{BaTiO}_{3}-\mathrm{SiO}_{2}$ compounded aerogels were heated at $800^{\circ} \mathrm{C}$.

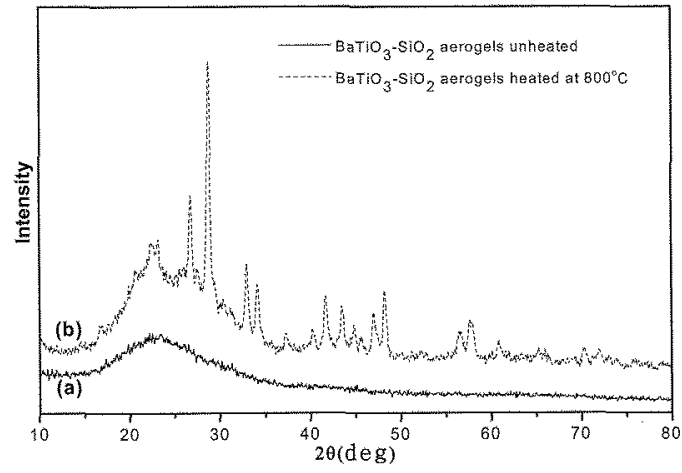

Fig. 4 XRD patterns of $\mathrm{BaTiO}_{3}-\mathrm{SiO}_{2}$ aerogels (b) heated at $800^{\circ} \mathrm{C}$ and (a) unheated at room temperature

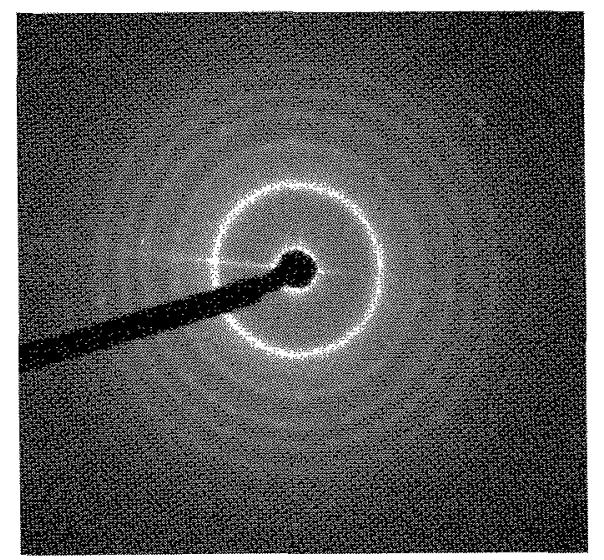

Fig.5 Electron diffraction pattern of $\mathrm{BaTiO}_{3}-\mathrm{SiO}_{2}$ aerogels heated at $800^{\circ} \mathrm{C}$

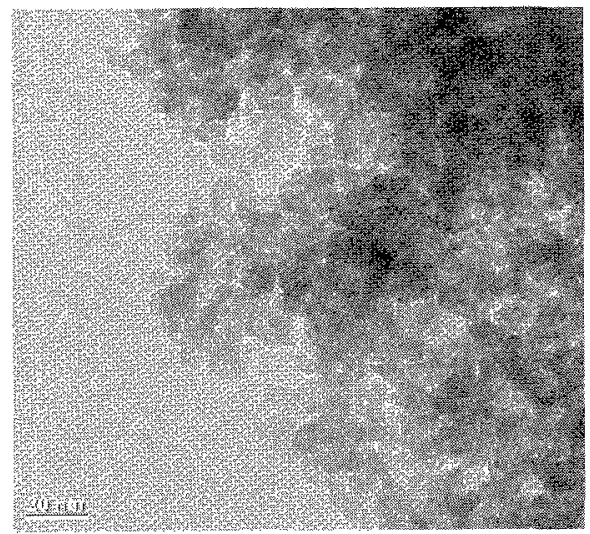

Fig. 6 TEM image of $\mathrm{BaTiO}_{3}-\mathrm{SiO}_{2}$ aerogels heated at $800^{\circ} \mathrm{C}$

The TEM image of $\mathrm{BaTiO}_{3}-\mathrm{SiO}_{2}$ aerogels heated at $800^{\circ} \mathrm{C}$ is shown in Fig. 6. The size distribution of the particles ranges from 7 to $20 \mathrm{~nm}$. The size and shape of $\mathrm{BaTiO}_{3}$ particles can be affected by the silica aerogels. The structural styles of $\mathrm{BaTiO}_{3}$ particles in silica aerogels were extracted that some $\mathrm{BaTiO}_{3}$ particles loaded in pores of silica aerogel and others entered into the lattices of silica aerogel. The growth mechanics of $\mathrm{BaTiO}_{3}$ particles in aerogels was that $\mathrm{BaTiO}_{3}$ particles were adsorbed by silica aerogel at the beginning, however, the growth of $\mathrm{BaTiO}_{3}$ particles was limited when $\mathrm{BaTiO}_{3}-\mathrm{SiO}_{2}$ aerogels were heated at $800^{\circ} \mathrm{C}$. The silica aerogel played a model role to limit the growth of $\mathrm{BaTiO}_{3}$ crystals. So the particle sizes of $\mathrm{BaTiO}_{3}$ in $\mathrm{BaTiO}_{3}-\mathrm{SiO}_{2}$ aerogels were less than ones of pure $\mathrm{BaTiO}_{3}$ powder.

\subsection{Optical characterization}

Fig.7 shows PL spectra of the $\mathrm{BaTiO}_{3}-\mathrm{SiO}_{2}$ aerogels heat treated for $2 \mathrm{hrs}$ at $800^{\circ} \mathrm{C}$ in the air and the $\mathrm{BaTiO}_{3}$ powder heat treated at $700^{\circ} \mathrm{C}$ and $800^{\circ} \mathrm{C}$ in the air. According to the PL spectra of Fig.7, the intensity of the $\mathrm{PL}$ was not obviously changed when the heat treatment temperature of pure $\mathrm{BaTiO}_{3}$ powder was increased. However, the intensity of $\mathrm{BaTiO}_{3}-\mathrm{SiO}_{2}$ compounded aerogels increased when they were heated at $800^{\circ} \mathrm{C}$. Fig.7 shows that the shapes of curves are not changed. This finding indicated strongly that the room- temperature PL stemmed from the $\mathrm{BaTiO}_{3}$ nanoparticles. A comparison of the different samples revealed that the PL behavior of the $\mathrm{BaTiO}_{3}-\mathrm{SiO}_{2}$ compounded aerogels was stronger than the ones of pure $\mathrm{BaTiO}_{3}$ powder. It was possible because the $\mathrm{BaTiO}_{3}$ nanoparticles of $\mathrm{BaTiO}_{3}-\mathrm{SiO}_{2}$ compounded aerogels were less than the ones of pure $\mathrm{BaTiO}_{3}$ powder. 


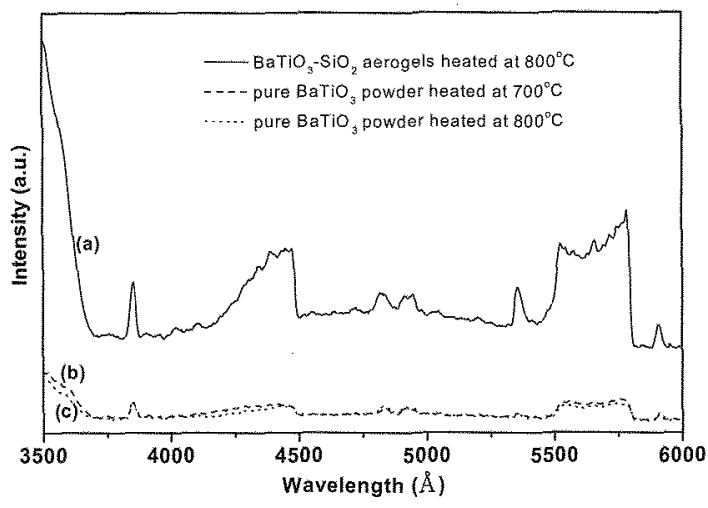

Fig.7 PL spectra of $\mathrm{BaTiO}_{3}-\mathrm{SiO}_{2}$ compounded aerogels heated at $800^{\circ} \mathrm{C}$ (a) and pure $\mathrm{BaTiO}_{3}$ powder heated at $700^{\circ} \mathrm{C}(\mathrm{b})$ and $800^{\circ} \mathrm{C}(\mathrm{c})$

\section{CONCLUSIONS}

$\mathrm{BaTiO}_{3}$ nanoparticles dispersed silica aerogel were prepared by a sol-gel route combined with supercritical drying method. There was good crystallinity when the $\mathrm{BaTiO}_{3}-\mathrm{SiO}_{2}$ aerogels were heated at $800^{\circ} \mathrm{C}$. $\mathrm{BaTiO}_{3}$ nanoparticels were loaded in the silica aerogel matrix with the sizes from 7 to $20 \mathrm{~nm}$. Silica aerogel played a model role to limit the growth of $\mathrm{BaTiO}_{3}$ nanoparticles in compounded aerogels when $\mathrm{BaTiO}_{3}-\mathrm{SiO}_{2}$ aerogels were heated at $800^{\circ} \mathrm{C}$, so the particles of $\mathrm{BaTiO}_{3}-\mathrm{SiO}_{2}$ aerogels were less than the ones of pure $\mathrm{BaTiO}_{3}$ powder. The $\mathrm{PL}$ intensity of $\mathrm{BaTiO}_{3}-\mathrm{SiO}_{2}$ aerogels heated at $800^{\circ} \mathrm{C}$ was stronger than the ones of pure $\mathrm{BaTiO}_{3}$ powder heated at $700^{\circ} \mathrm{C}$ and $800^{\circ} \mathrm{C}$. The properties and components of compounded aerogels will be investigated further in future work when $\mathrm{BaTiO}_{3}-\mathrm{SiO}_{2}$ aerogels are heated at different temperatures.

\section{ACKNOWLEDGEMENT}

This research is supported by a grant from the NITECH 21 st Century COE program, "World Ceramics Center for Environment Harmony".

\section{REFERRENCE}

[1]C.J. Brinker, G.W. Scherer, Sol-Gel Science, The Physics and Chemistry of Sol-Gel Processing, Academic Press, New York, 1989, ISBN 0-12-134970-5.

[2]L.W. Hrubesh, Chem. Industry 24 (1989) 824.

[3]C.J. Brinker, R.J. Kirkpatrick, D.R. Tallant, B.C. Bunker, J. Non-Cryst. Solids 99(1988) 418

[4]L.C. Klein (Ed.), Sol-Gel Technology for Thin Films, Fibers, Preforms, Electronics and Specialty shapes, Noyes, Park Ridge, NJ, 1987.

[5]L.Z. Yao, C.H. Ye, C.M. Mo. W.L. Cai, L.D. Zhang, J. Cryst. Growth 216, 147-151(2000).

[6]S. Grandi, P. Mustarelli, A. Magistris, M. Gallorini, E. Rizzio. J. Non-Cryst. Solids 303 208-217 (2002).

[7].C. Miller, D.A. Kleinman, A. Savage, Phys. Rev. Lett. 11(4), 146-149 (1963).

[8]Yong Yang, Jianlin Shi, Weiming Huang,
Shugang Dai, Lin Wang, Mater. Lett. 56 1048-1052(2002).

[9]Weiling Luan, Lian Gao, Cera. Intel. 27 645-648 (2001).

[10]Keigo Suzuki, Kazunori Kijima, J.Ceram. Soc. Jpn. Supplement 112-1, Pacrim5 Special Issue, 112 (5) S916-S923 (2004).

[11]Keigo Suzuki and Kazunori Kijima, Jpn. J. Appl. Phys., 44(4A) 2081-2082 (2005).

[12]Uchino,K., Sadamaga, E., Oonish, T, Morohashi, T. , Yamamura, H., Ceram. Transactions. 8,107 (1980).

[13]Frey, M. H., Payne D. A., Appl. Phys. Lett. 63(20) 2753 (1993).

[14]Yong-I. Kim, Jae Kap Jung, Kwon Sang Ryu, Mater. Res. Bull., 39 1045-1053 (2004).

[15]Song Wei Lu, Burtrand I. Lee, Zhong Lin Wang, Willian D. Samuels, J. Cryst. Growth 219 269-276 (2000).

(Received December 10, 2006;Accepted January 31, 2007) 